\title{
Correct Use of Facemask Among Health Professionals in the Context of Coronavirus Disease (COVID-19)
}

This article was published in the following Dove Press journal: Risk Management and Healthcare Policy

\author{
Yohannes Tekalegn (D) \\ Biniyam Sahiledengle (ID) \\ Kebebe Bekele ${ }^{2}$ \\ Abdi Tesemma ${ }^{2}$ \\ Tesfaye Aseffa $\left.{ }^{3}\right)^{3}$ \\ Zinash Teferu Engida' \\ Alemu Girma ${ }^{2}$ \\ Alelign Tasew (1D' \\ Demisu Zenbaba $(\mathbb{D})^{\prime}$ \\ Rameto Aman (1) ' \\ Kenbon Seyoum (iD) ${ }^{4}$ \\ Demelash Woldeyohannes $\left(\mathbb{D}^{5}\right.$ \\ Birhan Legese ${ }^{6}$ \\ 'Department of Public Health, Madda \\ Walabu University, Goba Referral Hospital, \\ School of Health Sciences, Bale-Goba, \\ Ethiopia; ${ }^{2}$ Department of Surgery, Madda \\ Walabu University, Goba Referral Hospital, \\ School of Medicine, Bale-Goba, Ethiopia; \\ ${ }^{3}$ Department of Nursing, Madda Walabu \\ University, Goba Referral Hospital, School \\ of Health Sciences, Bale-Goba, Ethiopia; \\ ${ }^{4}$ Department of Midwifery, Madda Walabu \\ University, Goba Referral Hospital, School \\ of Health Sciences, Bale-Goba, Ethiopia; \\ ${ }^{5}$ Department of Public Health, Wachemo \\ University, School of Medicine and Health \\ Sciences, Hossana, Ethiopia; ${ }^{6}$ Department \\ of Public Health, Ambo University, School \\ of Medicine and Health Sciences, Ambo, \\ Ethiopia
}

Correspondence: Yohannes Tekalegn Madda Walabu University, Goba Referral Hospital, School of Health Sciences, Department of Public Health, Addis Ababa 22847 code 1000, Ethiopia Tel +25l 91357890।

Email yohannesefa@gmail.com
Purpose: Coronavirus disease (COVID-19) mainly spreads through respiratory droplets and close contacts. Wearing a facemask and other personal protective equipment (PPE) is essential in preventing the spread of COVID-19. However, the use of PPE alone does not provide a sufficient level of protection, and correct use and disposal are required. Hence, this study aimed to assess health professionals' practice regarding proper use of facemask in the perspectives of COVID-19 prevention.

Methods: A web-based online survey was conducted from June 3, 2020, to August 11, 2020, to assess health professionals' practice regarding correct use of facemask. The survey tool was prepared in Google form and distributed to the health professionals through their emails and social media pages. Data were analyzed using STATA version 14. A descriptive result was reported using frequency tables and bar charts. Factors associated with correct use of facemask were assessed using binary logistic regression model.

Results: A total of 368 health professionals have participated in this study. All of the participants' work involves direct contact with patients and 98 (26.6\%) of them work in direct contact with COVID-19 patients daily. The level of overall correct use of facemask was $10.1 \%$ (95\% CI: 7.4-13.6). Two hundred fifty-five (69.3\%) do not perform hand hygiene before wearing a facemask and $238(64.7 \%)$ do not perform hand hygiene after removing the facemask. Three hundred twenty-three $(87.8 \%)$ of the study participants reuse disposable facemasks. The odds of practicing correct use of facemask were more than two times higher among health professionals who received training related to personal protective equipment utilization (AOR $=2.2,95 \% \mathrm{CI}: 1.1-4.5)$ compared to their counterparts.

Conclusion: This study revealed that health professionals' practice regarding the correct use of facemask in the context of COVID-19 prevention is very low. Receiving training related to proper utilization of personal protective equipment was found to favor the correct use of facemask. In this regard, health authorities should provide training to enable the rational and correct use of facemask among healthcare workers.

Keywords: COVID-19, facemask, healthcare workers, infection, prevention, Ethiopia

\section{Introduction}

Coronavirus disease 2019 (COVID-19) is first detected in Wuhan, China in December 2019. ${ }^{1,2}$ The spread of the COVID-19 virus occurs through direct, indirect, or close contact with an infected person through respiratory droplets. The droplets may also contaminate the surfaces around the infected person and can serve as a potential source for infection. ${ }^{3,4}$ Airborne transmissions of COVID-19 can also occur in healthcare setups during aerosol-generating procedures such as endotracheal intubation, cardiopulmonary 
resuscitation, manual ventilation before intubation, and bronchoscopy. ${ }^{4,5}$ World Health Organization (WHO) declared COVID-19 as a global public health emergency in January $2020{ }^{6}$ As of September 21, 2020, more than 30.6 million cases and 950,000 deaths from COVID-19 were reported to the WHO. ${ }^{7}$ Evidence suggests that COVID-19 infection among healthcare workers accounts for $10-20 \%$ of diagnosed cases. ${ }^{8,9}$

Preventive and mitigation measures are critical in combating this global challenge both in a community and healthcare setups. ${ }^{5,12}$ In community setups, preventive measures such as hand hygiene, physical distancing, practicing respiratory hygiene, and wearing medical masks were recommended by the World Health Organization. ${ }^{5}$ Healthcare workers are a highly vulnerable group due to their close contact with infected persons and risky working environment. ${ }^{10,11}$ Use of medical mask, gown, gloves, and eye protection (goggles or face shield) is recommended for healthcare workers providing direct care for COVID-19. $5,12,13$

Evidence revealed that consistent and correct use of personal protective equipment (PPE) is effective in protecting healthcare workers from acquiring healthcareassociated infections. ${ }^{14-16}$ However, failure to use PPE appropriately and consistently is associated with highrisk infection among healthcare workers. ${ }^{17}$ Several studies before the COVID-19 pandemic reported that health professionals' compliance to correct utilization of PPE was suboptimal in Ethiopia. ${ }^{18-20}$ However, health professionals' compliance with proper utilization of PPE during the COVID-19 pandemic is still unknown in Ethiopia. Consequently, having poor compliance to correct utilization of PPE during the COVID-19 pandemic could harm the scarce health system of developing countries like Ethiopia. Therefore, this study aimed to assess health professionals' practice regarding correct utilization of facemask in terms of COVID-19 prevention during the pandemic in Ethiopia.

\section{Methods}

\section{Study Population and Period}

A web-based cross-sectional survey was conducted among health professionals working in Ethiopia to assess their practice regarding the correct use of facemask. Ethiopia is one of the countries in the world with a low health workforce density of $0.7 / 1000$ population, which is far below the minimum threshold density of 2.3 health workers (Medical doctors, Nurses and Midwives) per 1000 population for countries to achieve essential services. ${ }^{21}$ All health professionals working either in government or private sectors were source population for the study. The study was conducted during the COVID-19 pandemic from June 3, 2020 to August 11, 2020.

\section{Sampling and Data Collection Procedures}

Data were collected through a structured, web-based, and self-administered questionnaire. First, questionnaires were developed by reviewing different literature regarding the rational use of facemask. ${ }^{5,22,23}$ The tool is composed of questions regarding socio-demographic and work-related characteristics and questions concerning health professionals' practice on the correct utilization of face masks. The questionnaire is prepared in English and converted to Google form. The developed Google form link was shared with the health professionals through their email address, Facebook, and Telegram. To complement the data collection process, the Google form was shared on official social media pages and groups of different Ethiopian health professional associations/unions. The sample size was calculated using a single population proportion formula. Considering $50 \%$ proportion, $95 \%$ level of confidence, and a $5 \%$ margin of error; the final sample size becomes 384 . The link to the online Google form is found at https://docs.google.com/forms/d/e/ 1FAIpQLSc-N0MNjF6fxrz382esKMWL2W-8CiqwYS TAq3PLd3VJZSnWA/viewform?usp=sf link

\section{Outcome Variable}

\section{Correct Use Facemask}

Correct use of facemask is derived from a series of six questions: 1) Do you perform hand hygiene before putting a facemask on? (1. Yes, 2. No); 2) Do you perform hand hygiene after removing the facemask? (1. Yes, 2. No); 3) DO you put facemask before contact with the patient? (1. Yes, 2. No); 4) Do you put a facemask on in a patient transit area? (1. Yes, 2. No); 5) Do you adjust your facemask during patient care? (1. Yes, 2. No); 6) Do you reuse facemask? (1. Yes, 2. No). If respondents answer "yes" to question number 1, 2, 3, 4 , and "no" to questions number 5, and 6; it is recorded as correct use of facemask, otherwise incorrect use.

\section{Independent Variables}

Independent variables were variables such as age, work experience, professional category, types of healthcare facilities, average working hours per day, direct contact with any patients, direct contact with COVID-19 patients, and training related to personal protective equipment utilization. 


\section{Data Analysis Procedures}

The collected data were downloaded from Google form in the excel spreadsheet. Then, the data was cleaned and exported to STATA version 14. Results regarding socio-demographic characteristics and practices regarding utilization of the facemasks were reported in the form of a frequency distribution table. The association between correct use of facemask and independent variables was assessed using a binary logistic regression model. Variable with a p-value of less than 0.2 in the bivariate binary logistic regression model was included in the multivariate binary logistic regression model. Multicollinearity between independent variables was checked using a variance inflation factor (VIF). Model fitness was checked using the Hosmer and Lemeshow goodness of fit test.

\section{Ethical Considerations}

Ethical clearance to conduct the study was obtained from the Madda Walabu University Goba Referral hospitals research ethics committee. Information regarding the aim of the study, the confidentiality of responses, and voluntary participation in the survey were clearly described on the first page of the online tool. All participants were asked to proceed to the survey questions after reading the information sheet and their voluntary participation consent was recorded. To ensure the anonymity of the responses, personal identifiers were not included in the survey questions. Furthermore, the collected data were stored in a passwordprotected computer to prevent unauthorized access.

\section{Results}

\section{Socio-Demographic Characteristics of Sampled Health Professionals}

A total of 368 health professionals who have direct contact with patients daily were included in this analysis. Of the total, about 309 (84\%) were male. In terms of region, large proportions of respondents were from the Oromia region and Addis Ababa city administration. Most of the study participants were working in hospitals (Table 1).

\section{Workplace-Related Characteristics}

Of the total, about 98 (26.6\%) of the health professionals' work involves direct contact with COVID-19 cases. One hundred fifty-eight $(42.9 \%)$ of the health professionals received training related to proper use of personal protective equipment (PPE) (Table 2).
Table I Socio-Demographic Characteristics of Sampled Health Professionals, Ethiopia, 2020

\begin{tabular}{|c|c|c|}
\hline Variables & Frequency & Percent \\
\hline \multicolumn{3}{|l|}{ Age category } \\
\hline$<40$ years & 349 & 94.8 \\
\hline$\geq 40$ years & 19 & 5.2 \\
\hline \multicolumn{3}{|l|}{ Sex } \\
\hline Female & 59 & 16.0 \\
\hline Male & 309 & 84.0 \\
\hline \multicolumn{3}{|l|}{ Work experience } \\
\hline$\leq 5$ years & 188 & 51.1 \\
\hline$>5$ years & 180 & 48.9 \\
\hline \multicolumn{3}{|l|}{ Professional category } \\
\hline Physicians $^{\mathrm{a}}$ & 182 & 49.5 \\
\hline Nurse/Midwives & 118 & 32.1 \\
\hline $\begin{array}{l}\text { Environmental health and public health } \\
\text { specialties }\end{array}$ & 24 & 6.5 \\
\hline Others $^{\mathrm{b}}$ & 44 & 11.9 \\
\hline \multicolumn{3}{|l|}{ Working region } \\
\hline Oromia & 199 & 54.1 \\
\hline Addis Ababa & 109 & 29.6 \\
\hline Somali & 5 & 1.4 \\
\hline SNNPR ${ }^{c}$ & 19 & 5.1 \\
\hline Amhara & 12 & 3.3 \\
\hline Harari & 9 & 2.4 \\
\hline Diredawa & 7 & 1.9 \\
\hline Tigray & 4 & 1.1 \\
\hline Benishangul-Gumuz & 2 & 0.5 \\
\hline Afar & 1 & 0.3 \\
\hline Gambela & 1 & 0.3 \\
\hline \multicolumn{3}{|l|}{ Type of healthcare facility } \\
\hline Hospital & 253 & 68.7 \\
\hline Health center & 60 & 16.3 \\
\hline COVID-19 quarantine center & 7 & 1.9 \\
\hline COVID-19 treatment center & 11 & 3.0 \\
\hline Academic institution & 8 & 2.2 \\
\hline Others $^{d}$ & 29 & 7.8 \\
\hline \multicolumn{3}{|l|}{ Average working hours per day } \\
\hline$\leq 8$ hours & 125 & 34.0 \\
\hline$>8$ hours & 243 & 66.0 \\
\hline
\end{tabular}

Notes: ${ }^{a} \mathrm{HO}, \mathrm{MD}, \mathrm{DD} ;{ }^{\mathrm{b}}$ Anesthesia, psychiatry, laboratory, and pharmacy; ${ }^{\mathrm{c} S o u t h}$ nation, nationalities and peoples region; ${ }^{\mathrm{d} P r i v a t e}$ clinics, Blood bank, NGOs, Research centers, Health offices.

Abbreviations: $\mathrm{HO}$, health officers; MD, medical doctors; DD, dental doctors.

\section{Health Professionals' Practice Regarding Facemask Utilization}

The overall magnitude of correct use of facemask among health professionals was $10.1 \%$ (95\% CI: 7.4-13.6). About $30 \%$ and $42 \%$ did not wear facemask before contact with 
Table 2 Work-Related Characteristics of Sampled Health Professionals, Ethiopia, 2020

\begin{tabular}{|c|c|c|}
\hline Variables & Frequency & Percent \\
\hline \multicolumn{3}{|c|}{$\begin{array}{l}\text { Does your work involve direct contact with a known case of COVID- } \\
19 \text { ? }\end{array}$} \\
\hline No & 270 & 73.4 \\
\hline Yes & 98 & 26.6 \\
\hline \multicolumn{3}{|c|}{$\begin{array}{l}\text { Have you received any training related to personal protective } \\
\text { equipment utilization? }\end{array}$} \\
\hline No & 210 & 57.1 \\
\hline Yes & 158 & 42.9 \\
\hline \multicolumn{3}{|c|}{ Is there any reported case of COVID-19 in your town? } \\
\hline Yes & 212 & 57.6 \\
\hline No & 144 & 39.1 \\
\hline I do not know & 12 & 3.3 \\
\hline
\end{tabular}

patients and in the patient transit areas, respectively. Most $(60.6 \%)$ of health professionals adjust their facemask during patient care. Majority (87.8\%) of them use disposable facemasks more than one time (Figure 1).

\section{Factors Associated with Correct Use of a} Facemask

In multivariate binary logistic regression, health professionals who received training related to proper utilization of personal protective equipment (PPE) were 2.2 times more likely $(\mathrm{AOR}=2.2 ; 95 \% \mathrm{CI}: 1.1-4.5)$ to practice the correct use of facemask than their counterparts (Table 3).

\section{Discussion}

This study aimed to assess the practice of health professionals regarding the correct use of facemask in terms of Coronavirus disease 2019 (COVID-19) infection prevention during the pandemic. During the COVID-19 pandemic, it is vital to screen all patients for fever, contacts with confirmed cases of COVID-19, and travel history. ${ }^{24}$ Identifying suspected cases of COVID-19 in the healthcare setting is essential in protecting healthcare workers and patients from COVID-19 infection. ${ }^{25}$ Early evidence revealed that considerable numbers of health professionals were died by COVID19 while battling with this pandemic. ${ }^{26}$ The most frequently mentioned reason for COVID-19 infections and deaths among health professionals was the lack/shortage of personal

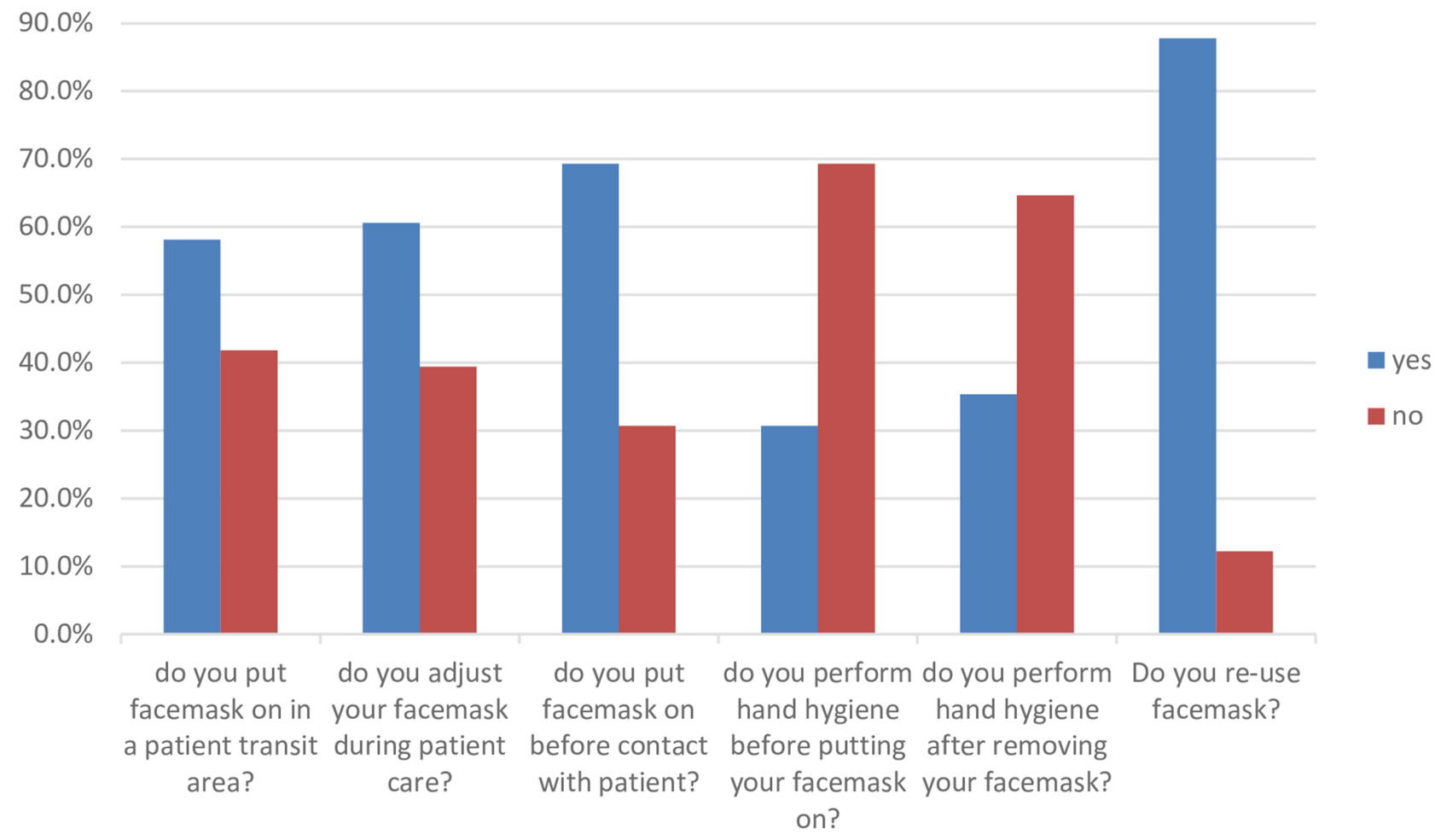

Figure I Practice of health professionals regarding the utilization of facemask during COVID-19 pandemic, Ethiopia, 2020. 
Table 3 Factors Associated with Correct Use of Facemask Among Health Professionals Working in Direct Contact with Patients During COVID-19 Pandemic, Ethiopia, 2020

\begin{tabular}{|c|c|c|c|c|}
\hline \multirow[t]{2}{*}{ Variables } & \multicolumn{2}{|c|}{ Correct Use of a Facemask } & \multirow[t]{2}{*}{ COR $(95 \% \mathrm{Cl})$} & \multirow[t]{2}{*}{$\operatorname{AOR}(95 \% \mathrm{Cl})$} \\
\hline & Yes, n (\%) & No, n (\%) & & \\
\hline \multicolumn{5}{|l|}{ Age category } \\
\hline$<40$ years & $37(10.6)$ & $312(89.4)$ & I & \\
\hline$\geq 40$ years & $2(10.5)$ & $17(89.5)$ & $0.9(0.2-4.4)$ & \\
\hline \multicolumn{5}{|l|}{ Work experience } \\
\hline$\leq 5$ years & $21(11.2)$ & $167(88.2)$ & I & \\
\hline$>5$ years & $18(10.0)$ & $162(90.0)$ & $0.9(0.5-1.7)$ & \\
\hline \multicolumn{5}{|l|}{ Professional category } \\
\hline Physicians $^{\mathrm{a}}$ & $20(11.0)$ & $162(89.0)$ & 1 & 1 \\
\hline Nurse/Midwifes & $10(8.5)$ & $108(91.5)$ & $0.7(0.3-1.6)$ & $0.7(0.3-1.5)$ \\
\hline Environmental health and public health specialties & $3(12.5)$ & $21(87.5)$ & $1.2(0.3-4.2)$ & $0.9(0.2-3.8)$ \\
\hline Others $^{b}$ & $4(9.1)$ & $40(90.9)$ & $0.8(0.2-2.5)$ & $0.8(0.2-2.5)$ \\
\hline \multicolumn{5}{|l|}{ Type of healthcare facility } \\
\hline Hospitals & $23(9.1)$ & $230(90.9)$ & I & 1 \\
\hline Health centre & $4(6.7)$ & $56(93.3)$ & $0.7(0.2-2.1)$ & $0.7(0.2-2.2)$ \\
\hline COVID-19 quarantine/treatment center & $5(27.8)$ & $13(72.2)$ & $3.8(I .2-11.8)$ & $2.6(0.7-9.4)$ \\
\hline Others $^{c}$ & $5(13.5)$ & $32(86.5)$ & $1.5(0.5-4.4)$ & $1.7(0.5-5.1)$ \\
\hline \multicolumn{5}{|l|}{ Average working hours per day } \\
\hline$\leq 8$ hours & $10(8.0)$ & $115(92.0)$ & I & 1 \\
\hline$>8$ hours & $27(\mathrm{II} .1)$ & $216(88.9)$ & $1.4(0.7-3.0)$ & $1.6(0.7-3.5)$ \\
\hline \multicolumn{5}{|l|}{$\begin{array}{l}\text { Does your work involve direct contact with a } \\
\text { known case of COVID-19? }\end{array}$} \\
\hline No & $25(9.3)$ & $245(90.7)$ & I & 1 \\
\hline Yes & $12(12.2)$ & $86(87.8)$ & $\mathrm{I} .4(0.7-2.8)$ & I. $2(0.5-2.8)$ \\
\hline \multicolumn{5}{|l|}{$\begin{array}{l}\text { Have you received any training related to personal } \\
\text { protective equipment utilization? }\end{array}$} \\
\hline No & $14(6.7)$ & $196(93.3)$ & I & 1 \\
\hline Yes & $23(14.6)$ & $135(85.4)$ & $2.4(1.2-4.8)$ & $2.2(1.1-4.5)^{* *}$ \\
\hline
\end{tabular}

Notes: **Significant at P-value less than $0.05 ;{ }^{a} \mathrm{HO}, \mathrm{MD}, \mathrm{DD} ;{ }^{\mathrm{b}}$ Anesthesia, psychiatry, laboratory, and pharmacy; ${ }^{\mathrm{C}}$ Private clinics, Blood bank, NGOs, Research centers, Health offices, and academic institutions.

Abbreviations: COR, crude odds ratio; $\mathrm{AOR}$, adjusted odds ratio; $\mathrm{Cl}$, confidence intervals; $\mathrm{HO}$, health officers; $\mathrm{MD}$, medical doctors; $\mathrm{DD}$, dental doctors.

protective equipment (PPE) ${ }^{27}$ Even in the presence of adequate PPE, correct practice during donning and doffing techniques is critical in preventing infections. ${ }^{5,28}$ World Health Organization (WHO) recommends health professionals to implement standard precautions all the time. Additionally, contact and droplet precautions should be in place until the patient is asymptomatic. $^{23}$

In this study, among health professionals' whose work involves direct contact with patient, only $10 \%$ of them use facemask according to the World Health Organization (WHO) mask management recommendation. ${ }^{22}$ About 69\% of health professionals wear facemask before contact with a patient. According to the $\mathrm{WHO}$ recommendations, all healthcare workers and caregivers working in clinical areas and areas with COVID-19 community transmission should wear facemask continuously throughout the entire shift to protect themselves as well as patients from COVID-19 infection. ${ }^{22}$ Furthermore, to prevent contamination of the facemask during wearing and removing, it is recommended to perform hand hygiene before wearing the facemask and after removing it. In this study, only $30 \%$ of health professionals perform hand hygiene before wearing a facemask. Similarly, about $35 \%$ of health professionals perform hand hygiene after removing the facemask. During donning and doffing of PPE, there are possibilities of touching the contaminated surfaces. ${ }^{29}$ Therefore, performing hand hygiene 
with both soap and water or alcohol-based hand rub is highly recommended. In this study, there is a gap in performing hand hygiene before and after using PPE, which might increase the risks of contracting COVID-19 and other infectious diseases among health professionals and patients.

Another very important finding of this study is the majority $(88 \%)$ of health professionals who participated in this survey were reusing single-use facemasks. WHO recommends disposing of single-use facemasks immediately upon removal and after use. ${ }^{22}$ A prospective cohort study in the UK and the USA reported that front-line healthcare workers who reuse PPE had a 1.5 times higher risk of being tested positive for COVID-19 compared to healthcare workers who reported adequate PPE. ${ }^{11}$ This disturbingly high magnitude of facemask reuse might be related to the global shortage of PPE as well as in Ethiopia. Unless attention is given and appropriate corrective action is taken, this trend might result in high COVID19 infection among healthcare workers.

In line with previous studies, health professionals who received training on proper utilization of PPE were 2.2 times more likely to correctly use a facemask. A study by Hon et al reported that training on infection control courses is capable of transferring knowledge regarding the appropriate selection and use of PPE. ${ }^{30}$ Even though it is not statistically significant but worthy of clinical attention, health professionals working in the COVID-19 treatment or quarantine centers were 2.6 times more likely to correctly use facemask than other health professionals working in non-COVID-19 dedicated hospitals. This finding might be vindicated through the hypothesis that health professionals working in the COVID-19 might have a high perceived risk of infection and more likely to be vigilant to practice recommended infection prevention protocols. Furthermore, healthcare workers in COVID-19 treatment/ quarantine centers might have relatively better infrastructure and supplies of PPE compared to those working in non-COVID-19-dedicated health facilities.

\section{Limitations}

This study suffers from several limitations and the result shall be used carefully. First, the study used the selfreported practice of health professionals. Second, since the study used a web-based survey, the study participants were limited to social media and internet users. Third, the reason for facemask re-use among health professionals' was not explored by this study. Fourth, due to the underrepresentation of some regions, the study findings might not reflect the actual situation of the entire country. Fifth, due to the cross-sectional nature of the study, the study might not reflect the cause-effect relationship between dependent and independent variables. At last, personal protective equipment other than facemask was not included in this study.

\section{Conclusion}

This study revealed that health professionals' practice regarding the correct use of facemask is very low. Nearly, $90 \%$ of the health professionals reuse single-use facemasks and most of them did not perform hand hygiene before and after using a facemask. Health professionals who received training related to proper utilization of personal protective equipment were more likely to carry out the correct use of facemask. In this regard, health authorities should provide training to enable the rational and correct use of facemask among healthcare workers.

\section{Abbreviations}

COVID-19, coronavirus disease; PPE, personal protective equipment; WHO, World Health Organization; AOR, adjusted odds ratio; COR, crudes odds ratio; $\mathrm{CI}$, confidence interval.

\section{Data Sharing Statement}

Data are available from the corresponding author upon a reasonable request.

\section{Acknowledgments}

We would like to thank all study participants take part in this survey.

\section{Author Contributions}

All authors made a significant contribution to the work reported, whether that is in the conception, study design, execution, acquisition of data, analysis and interpretation, or in all these areas; took part in drafting, revising or critically reviewing the article; gave final approval of the version to be published; have agreed on the journal to which the article has been submitted; and agree to be accountable for all aspects of the work.

\section{Disclosure}

The authors report no conflicts of interest in this work. 


\section{References}

1. Bogoch II, Watts A, Thomas-Bachli A, Huber C, Kraemer MU, Khan K. Pneumonia of unknown aetiology in Wuhan, China: potential for international spread via commercial air travel. J Travel Med. 2020;27 (2):taaa008. doi:10.1093/jtm/taaa008

2. Lu H, Stratton CW, Tang YW. Outbreak of pneumonia of unknown etiology in Wuhan, China: the mystery and the miracle. $J$ Med Virol. 2020;92(4):401-402. doi:10.1002/jmv.25678

3. Organization WH. Water, Sanitation, Hygiene, and Waste Management for SARS-Cov-2, the Virus That Causes COVID-19: Interim Guidance, 29 July 2020. World Health Organization; 2020.

4. Organization WH. Transmission of SARS-Cov-2: Implications for Infection Prevention Precautions: Scientific Brief, 09 July 2020. World Health Organization; 2020.

5. Organization WH. Rational Use of Personal Protective Equipment for Coronavirus Disease (COVID-19): Interim Guidance, 27 February 2020. World Health Organization; 2020.

6. World Health Organization. Statement on the second meeting of the international health regulations. Emergency committee regarding the outbreak of novel coronavirus (2019- nCoV); 2005 [cited March 28, 2020]; 2005. Available from: https://www.who.int/newsroom/detail/ 30-01-2020-statement-onthe-second-meeting-of-theinternationalhealth-regulations.

7. Organization WH. Coronavirus Disease (COVID-19) Weekly Epidemiological and Operational Updates September 21. [Report]. 2020.

8. CDC COVID-19 response team. Characteristics of Health Care Personnel with COVID-19-United States, February 12-April 9, 2020. 2020.

9. Lazzerini M, Putoto G. COVID-19 in Italy: momentous decisions and many uncertainties. Lancet Glob Health. 2020;8(5):e641-e2.

10. Black JR, Bailey C, Przewrocka J, Dijkstra KK, Swanton C. COVID19: the case for health-care worker screening to prevent hospital transmission. Lancet. 2020;395(10234):1418-1420. doi:10.1016/ S0140-6736(20)30917-X

11. Nguyen LH, Drew DA, Graham MS, et al. Risk of COVID-19 among front-line health-care workers and the general community: a prospective cohort study. Lancet Public Health. 2020;5(9):e475-e83. doi:10.1016/S2468-2667(20)30164-X

12. Wang Y, Zeng L, Yao S, et al. Recommendations of protective measures for orthopedic surgeons during COVID-19 pandemic. Knee Surg Sports Traumatol Arthrosc. 2020;1-9.

13. Hirschmann MT, Hart A, Henckel J, Sadoghi P, Seil R, Mouton C. COVID-19 coronavirus: recommended personal protective equipment for the orthopaedic and trauma surgeon. Knee Surg Sports Traumatol Arthrosc. 2020;28(6):1690. doi:10.1007/s00167-02006022-4

14. Verbeek JH, Rajamaki B, Ijaz S, et al. Personal protective equipment for preventing highly infectious diseases due to exposure to contaminated body fluids in healthcare staff. Cochrane Database Syst Rev 2020;(4).
15. Casanova L, Alfano-Sobsey E, Rutala WA, Weber DJ, Sobsey M. Virus transfer from personal protective equipment to healthcare employees' skin and clothing. Emerg Infect Dis. 2008;14(8):1291. doi:10.3201/eid1408.080085

16. Howard BE. High-risk aerosol-generating procedures in COVID-19: respiratory protective equipment considerations. Otolaryngol Head Neck Surg. 2020;0194599820927335.

17. Lau JT, Fung KS, Wong TW, et al. SARS transmission among hospital workers in Hong Kong. Emerg Infect Dis. 2004;10(2):280. doi:10.3201/eid1002.030534

18. Haile TG, Engeda EH, Abdo AA. Compliance with standard precautions and associated factors among healthcare workers in Gondar University comprehensive specialized hospital, Northwest Ethiopia. J Environ Public Health. 2017;2017:2050635. doi:10.1155/2017/ 2050635

19. Gebreselassie FT. Investigating the Compliance with Universal Precautions Among Health Care Providers in Tikur Anbessa Central Referral Hospital. Addis Ababa, Ethiopia: University of Western Cape; 2009.

20. Sahiledengle B, Gebresilassie A, Getahun T, Hiko D. Infection prevention practices and associated factors among healthcare workers in governmental healthcare facilities in Addis Ababa. Ethiop J Health Sci. 2018;28(2):177-186. doi:10.4314/ejhs.v28i2.9

21. Organization WH. The World Health Report 2006: Working Together for Health. World Health Organization; 2006.

22. Organization WH. Advice on the Use of Masks in the Context of COVID-19: Interim Guidance, 5 June 2020. World Health Organization; 2020.

23. Organization WH. Infection Prevention and Control During Health Care When COVID-19 is Suspected: Interim Guidance, 19 March 2020. World Health Organization; 2020.

24. Meng L, Hua F, Bian Z. Coronavirus disease 2019 (COVID-19): emerging and future challenges for dental and oral medicine. $J$ Dent Res. 2020;99(5):481-487. doi:10.1177/0022034520914246

25. Samaranayake LP, Peiris M. Severe acute respiratory syndrome and dentistry: a retrospective review. $J$ Am Dent Assoc. 2004;135 (9):1292-1302. doi:10.14219/jada.archive.2004.0405

26. Ing E, Xu Q, Salimi A, Torun N. Physician deaths from corona virus (COVID-19) disease. Occup Med (Chic Ill). 2020;70(5):370-374. doi:10.1093/occmed/kqaa088

27. Salvatori GE. Italian Doctor Dies of Coronavirus After Working Without Gloves Due to Shortage [Online]. 2020.

28. Jefferson T, Del Mar CB, Dooley L, et al. Physical interventions to interrupt or reduce the spread of respiratory viruses. Cochrane Database Syst Rev. 2011;(7).

29. Chughtai AA, Chen X, Macintyre CR. Risk of self-contamination during doffing of personal protective equipment. Am J Infect Control. 2018;46(12):1329-1334. doi:10.1016/j.ajic.2018.06.003

30. Hon C-Y, Gamage B, Bryce EA, et al. Personal protective equipment in health care: can online infection control courses transfer knowledge and improve proper selection and use? Am J Infect Control. 2008;36(10):e33-e7. doi:10.1016/j.ajic.2008.07.007
Risk Management and Healthcare Policy

\section{Publish your work in this journal}

Risk Management and Healthcare Policy is an international, peerreviewed, open access journal focusing on all aspects of public health, policy, and preventative measures to promote good health and improve morbidity and mortality in the population. The journal welcomes submitted papers covering original research, basic science, clinical \& epidemiological studies, reviews and evaluations, guidelines, expert opinion and commentary, case reports and extended reports. The manuscript management system is completely online and includes a very quick and fair peer-review system, which is all easy to use. Visit http://www.dovepress.com/testimonials.php to read real quotes from published authors. 